\title{
Community sexually transmitted infection services are good enough: a qualitative study of clients' experiences
}

\author{
Jacqui Evans, Jill Cross
}

\begin{abstract}
Background Lewisham in South East London, UK has high rates of sexually transmitted infection (STI), termination of pregnancy and teenage conception. Greater community provision of STI services has been proposed nationally to address the current sexual health crisis but concern has been expressed about their quality. Lewisham Community Sexual and Reproductive Health (S\&RH) Department has been providing testing and treatment for uncomplicated STI since 2002.
\end{abstract}

Objective To explore the experiences of clients using a community STI service for testing and treatment.

Methods A qualitative study involving semi-structured interviews with 16 clients diagnosed with a STI and attending a South East London community STI service for treatment.

Results Three main themes emerged during the analysis. The environment in sexual health clinics is important in determining the degree of stigma experienced by these clients. Easy access to a STI service is an important factor in determining clients' choice of services. This local community STI service provided an acceptable and satisfactory service to these clients requiring uncomplicated STI treatment.

Conclusions This study demonstrates that a community STI service is acceptable to clients using a community $\mathrm{S} \& \mathrm{RH}$ service. More research is urgently needed to determine whether community STI treatment would be acceptable to client groups who do not currently use such a service.

Keywords community, qualitative research, sexually transmitted infection, STI

J Fam Plann Reprod Health Care 2007; 33(4): 259-262

(Accepted 6 December 2006)

\section{Introduction}

The decline in the nation's sexual health ${ }^{1,2}$ has resulted in an increasing demand for sexually transmitted infection (STI) services, which has overwhelmed many genitourinary medicine (GUM) departments.1,3 Greater community provision of STI services has been proposed but concern has been expressed about their quality.

Lewisham in South East London, UK has high rates of STI, termination of pregnancy and teenage conception. ${ }^{4}$ Local sexual health services are provided by a community sexual and reproductive health (S\&RH) service from walkin clinics at 10 sites (50354 consultations with 23310 clients, $48 \%$ of whom were aged $<25$ years in 2004/5) and by five local GUM services based in adjacent boroughs that run a mixture of walk-in and appointment clinics (where waiting times in the two largest services frequently exceed 3 and 4.5 hours, respectively). ${ }^{5}$

The community S\&RH service had traditionally provided a contraception and primary care gynaecology service with an infection service limited to testing when clinically indicated for Chlamydia trachomatis (CT), gonorrhoea, Trichomonas vaginalis (TV), bacterial vaginosis (BV) and vulvovaginal candidal infection and treatment for symptomatic candidiasis and BV. In 2002, treatment was introduced for uncomplicated STI (i.e. CT, $\mathrm{TV}$, primary genital herpes and genital warts) and subsequently for pelvic inflammatory disease and uncomplicated gonorrhoea. The National Chlamydia Screening Programme started in Lewisham in 2004. Predictably, infection-related work has become an

\section{Department of Sexual and Reproductive Health Care,} Lewisham Primary Care Trust, Honor Oak Health Centre, London, UK

Jacqui Evans, MRCGP, MFFP, Associate Specialist

Jill Cross, RGN, MA, Research Nurse

Correspondence to: Dr Jacqui Evans, Department of Sexual and Reproductive Health Care, Lewisham Primary Care Trust, 3rd Floor, Waldron Health Centre, Stanley Street, New Cross, London SE8 4BG, UK. E-mail: evaj@freeuk.com

\section{Key message points}

- Clients attending sexually transmitted infection (STI) services want rapid and effective treatment for their STI delivered in a discrete, confidential, supportive and nonjudgmental environment.

- The environment in sexual health clinics is an important factor in determining the degree of stigma experienced by these clients.

- Easy access to a STI service is a key factor in determining clients' choice of services.

- A community STI service is acceptable to clients using a community sexual and reproductive health service.

increasingly dominant part of the community workload as it has become more familiar to staff and clients. Between 2002 and 2005, whilst the number of clients increased by $25 \%$ (from 18641 to 23310 ) and cervical screening by $17 \%$ (from 4383 to 5140 ), the number of chlamydia tests taken increased by $122 \%$ (from 4691 to 10431 ) and the number of STIs treated increased by $263 \%$ (from 702 to 2549). A report of the first 6 months of the community STI service concluded that such a service was feasible and effective and actually more effective in treating chlamydia than referral to GUM clinics. ${ }^{6-8}$

Prompt attendance for treatment is vital if the current STI epidemic is to be brought under control. Service users' experiences have been shown to influence their healthseeking behaviour. The experience of clients attending hospital-based GUM services is well documented ${ }^{9}$ but there are very few published data about community STI services. ${ }^{10}$ This study aimed to explore the experiences of clients using such a service.

\section{Methods}

Design

A qualitative methodology was used. Ethics committee approval was granted to conduct semi-structured interviews based on an interview guide that was flexibly applied to allow clients to raise any issues they felt were important whilst ensuring that aspects that the researchers wanted to explore were covered in some depth. 


\section{Sample}

A sample of the first 16 clients using the community clinic STI service for treatment between September 2002 and September 2003 who agreed to be interviewed was recruited at three clinics by two clinician/researchers [JE, six clients; Paula Baraitser (PB), three clients], two clinicians (one client each) and a research nurse (five clients). Five clients (all females aged $<25$ years) who initially consented to be interviewed subsequently declined, mostly due to difficulty in contacting them or arranging a convenient interview time, and one client's interview tape was inaudible. It took 1 year to recruit 16 clients, by which time data saturation was apparent. The number of clients who declined to participate when asked and the reasons for this are unknown. Eventually it proved necessary for the researcher to wait in the largest clinic and ask clients to participate as they attended for STI treatment, offering to interview them there and then to boost recruitment. Three researchers were involved in order to provide the flexibility needed to recruit and retain the sample as each researcher had only limited availability due to other clinical commitments.

\section{Data collection}

Interviews were conducted at the clinics by three of the researchers working closely to a pre-agreed interview schedule to minimise differences in their interview style and content. The research nurse, who was not involved in any clinical care, conducted nine of the interviews. Two clinician/researchers conducted seven of the interviews, four of which were conducted by a researcher/clinician (JE) who had also been involved in the clients' clinical care. Three clients were interviewed at the clinic immediately after they had been treated for their infection and 13 came back to the clinic on a separate occasion. All interviews were audio-taped and fully transcribed.

\section{Data analysis}

Line-by-line analysis of the interview transcriptions by JE and $\mathrm{PB}$ resulted in the development of an initial coding framework, a process that involved 'constant comparison' of individual data segments with the rest of the data. ${ }^{11}$ The data segments were indexed according to this framework. By working with the raw data independently and together any differences in coding were resolved and themes were developed, modified and analysed by JE and PB to generate hypotheses, which were tested by deviant case analysis.

\section{Ethical approval}

Ethical approval was sought and granted by Kings and Lewisham Local Ethics Committees

\section{Results}

The sample was representative of the general clinic population attending for STI testing in terms of sex, age and ethnicity and STI treated but proportionately more of the sample was symptomatic at the time of testing (Table 1). There was a range of occupations (six students, two hairdressers, two retail assistants, one housewife, one administrator, one driver, one motor mechanic and one unknown). Five clients were new to the community service and eight had previous experience of GUM services.

Three main themes emerged during the analysis that were key to the clients' experience of STI services, supported by attributed illustrative quotations [e.g. (C10) being client number 10] and by the total number of clients expressing that view [e.g. (7) meaning seven clients expressed that view]. All deviant cases are fully reported. Any remaining clients did not express a view on that theme.
Table 1 Study sample $(n=16)$ compared to community service population tested for sexually transmitted infection

\begin{tabular}{|c|c|c|c|}
\hline Characteristic & $\begin{array}{l}\text { Sample } \\
\text { number } \\
(n)\end{array}$ & $\begin{array}{l}\text { Sample } \\
(\%)\end{array}$ & $\begin{array}{l}\text { Community } \\
\text { service } \\
\text { population } \\
\text { tested for } \\
\text { STI (\%) }\end{array}$ \\
\hline \multicolumn{4}{|l|}{ Sex } \\
\hline Female & 13 & 81 & 87 \\
\hline Male & 3 & 19 & 13 \\
\hline \multicolumn{4}{|l|}{ Age (years) } \\
\hline$<25$ & 10 & 63 & 57 \\
\hline $25-29$ & 2 & 13 & 16 \\
\hline $30-40$ & 3 & 19 & 19 \\
\hline Unknown/>40 & 1 & 6 & 8 \\
\hline \multicolumn{4}{|l|}{ Ethnicity } \\
\hline Black/BBC/BAC & 8 & 50 & 50 \\
\hline Mixed BBC/White & 4 & 25 & 4 \\
\hline White & 3 & 19 & 29 \\
\hline Unknown/other ethnicity & 1 & 6 & 17 \\
\hline \multicolumn{4}{|l|}{ Reason for testing } \\
\hline Symptomatic/known STI & 10 & 63 & 26 \\
\hline STI contact & 5 & 31 & 7 \\
\hline Asymptomatic screening & 1 & 6 & 67 \\
\hline \multicolumn{4}{|l|}{ STI treated } \\
\hline Chlamydia trachomatis & 10 & 41 & 40 \\
\hline Chlamydia contact & 4 & 25 & 23 \\
\hline Trichomonas vaginalis & 1 & 6 & 8 \\
\hline Genital warts & 1 & 6 & 9 \\
\hline
\end{tabular}

BAC, Black Afro-Caribbean; BBC, Black/Black British Caribbean; $\mathrm{STI}$, sexually transmitted infection.

\section{Access was easier at the community service}

Clients preferred to attend the community STI service as access was easier. It was local, easy to find, had convenient opening hours and a walk-in system. Seven of the eight clients who had experience of GUM services specified the proximity of the community clinic as being one of the main reasons they had chosen to come. Only one client thought attending a local clinic might compromise confidentiality.

"Cos when I went to $X$ and $Y$ [X and $\mathrm{Y}$ being two of the local GUM clinics] and stuff it's like quite a far journey, like just walk round the corner and in 10 minutes I'm here." (C10)

"This one [family planning clinic (FPC)] is better [than GUM] 'cos you can just walk in any time you want and it closes late as well, at eight so that's alright." (C7)

Seven of the eight clients who were experienced GUM users had experienced restricted access at GUM, resulting in their subsequent attendance at the community STI service. Two clients had been unable to make an early appointment and left after being faced with a 5-hour waiting time, two never went in due to long queues outside the clinic before it opened, and three had previous experience of very long waiting times.

"They [GUM] just said I could go either to see my GP or I could come to family planning or I could go to walk-in but that would mean I would have to sit and wait for hours and hours to be seen. I could go to X [GUM clinic] but again I have been there before one time and I was sitting there for 5 hours so I just thought, no I'm not doing it." (C8)

\section{The environment in sexual health clinics is very important to clients}

Most (13/16) of the clients interviewed had felt uncomfortable when attending sexual health services. Ten clients expressed negative feelings about judging themselves or being judged by others. Seven clients said 
they had particularly valued community staff for making them feel less stigmatised. Six clients experienced a need for emotional support, especially with a first STI diagnosis.

"My experience was alright. It wasn't as daunting as I thought it would be. She [the doctor] was really good about it. She asked me if I was worried about anything. She wasn't like 'Oh, you should have known better' and stuff like that. They're not judgmental about it. They're really open so it felt comfortable. I felt pretty relaxed about the whole situation. Don't feel it's all my fault." (C16)

Five of the eight clients who had experience of attending GUM and community services felt more comfortable attending community services mainly because they were perceived to be friendlier and less intimidating, one felt more comfortable at GUM as she had always seen the same doctor. Two expressed no preference.

"I prefer coming here [FPC] ... because the people are friendly. They are friendly here, they don't look intimidating." (C16)

Although generally satisfied with the confidentiality in the sexual health services they had attended, 10 clients expressed specific concerns with confidentiality in the reception area and waiting room of the community clinic and cited confidentiality as being of particular importance to them.

"The privacy at the reception desk I think there could be a bit more privacy to be quite honest, like giving your details there and then sometimes you need a bit more privacy ... You don't want anyone else to know, they cannot know." (C5)

Female sexual health clients want to be seen in an allfemale environment. Six female clients (three with GUM experience) preferred female staff and female clients, although exceptions were made for their own male partners. Interestingly, the three male clients who were attending the FPC didn't seem to feel intimidated.

"If it's just all women together like women know each others needs and feelings and stuff. Then there's like boys sitting and looking at you thinking what are you here for? You might even bump into past partners or something in the waiting room ... men should be able to come ... men should have their own space." (C10)

Six of the 11 experienced community clients said they felt more confident and satisfied with the service as they became more familiar with it.

"I first started coming [to the FPC] when I was 16 ... once I started coming here I got more confident so every time I noticed something different I'd be back straight away. It's better." (C11)

\section{Clients are generally satisfied with the service they have received from the community STI service}

All 16 clients said they were satisfied with the service they had received at the FPC. Degrees of satisfaction varied from "for the NHS this place is ok but you cannot expect luxury" (C2) to "I can say I thought everything was perfect. I was happy with everything from when I came in to when I left, even more happy when I left to know I have been treated ... coming to here has been fantastic for me." (C3)

Reasons for satisfaction included the proximity of the clinic (7), the fact that clients could walk in when it was convenient for them to attend (7) and walk out with their treatment (4) without needing to go to a pharmacy (2).
Clients also found the service friendly (6), informative (6) and non-judgmental (7).

"It's a nice environment, the people are nice, it's ladies who deal with you, it's quick and they sort of explain most of the things, they can treat you on the spot and they haven't got to send you to a pharmacy to go and get the medication or whatever. So that's quite good." (C15)

Of the eight clients who had experience of both FPC and GUM services, six preferred to attend the FPC for infection management because it was closer (4), friendlier and less intimidating (5), less crowded (2) and the reason for attendance was not immediately obvious (1). Despite the overall preference for the FPC, six of these clients made positive comments about the GUM service, which included the wider range of tests and treatments available (3), greater privacy with separate male and female waiting areas and being called by number rather than name (2) and the availability of counselling (2).

"It's unfriendlier the $X[\mathrm{GUM}]$ anyway ... It is difficult to admit that you have got an infection or anyone to think, but the way you are treated at this clinic [FPC] you do not feel so ostracised. At the X [local GUM] you know what everyone is there for but somehow you still feel uncomfortable ... here [FPC] nobody knows." (C1)

\section{Discussion}

These community clients wanted rapid and effective treatment for their STI delivered in a discrete, confidential, supportive and non-judgemental environment. Seven of the eight experienced GUM users chose to attend the community S\&RH service for STI advice and management because of previous difficulty in accessing GUM services. Community clients with STI experienced feelings of stigma and shame, which meant that the environment in sexual health clinics was particularly important to them and could determine the degree to which stigma was experienced. These aspects of STI management have been extensively documented in clients using GUM services. $1,3,10,12$

What did emerge from this study was that these clients, regardless of gender or previous experience of GUM services, found that their STI management was acceptable, satisfactory and often preferable in a community setting because access was easier and the environment was familiar and less intimidating. There is little published research about men who attend community S\&RH services as historically these clinics have been female spaces with men attending simply to collect condom supplies from the reception desk. The three male clients in our study didn't seem to feel intimidated, which might reflect the fact that men attending community clinics are often introduced by their female friends and partners. GUM services were valued for the wider range of tests (including serology for syphilis, HIV and hepatitis B) and treatment provided and the counselling services offered by health advisors, but ease of access and familiarity of the environment seemed more important to these clients in determining where they attended for STI management.

The conclusions that can be drawn from this study are limited by its very nature. It took 1 year to recruit the sample, despite offering a £20 gift voucher as compensation for the participants' time, and this may reflect the sensitivity of the subject matter as well as the failure of clinicians to recruit clients during busy sessions. The client sample, although representative of the community clinic population attending for STI testing in terms of sex, age, ethnicity and STI treated, may be 
unrepresentative of the general population of community or GUM clinic users. The fact that participants were prepared to talk about their experiences could indicate that they were either particularly satisfied or dissatisfied with the service they received. It is likely that the sample contains dissatisfied GUM users, as those that are satisfied are likely to continue to attend GUM services.

The three interviewers were employed by the community service and two were clinical staff. One interviewer (JE) had been involved in four of the clients' clinical care due to the difficulties in recruiting and retaining the sample and the limited availability of individual interviewers, however the remaining 12 clients were interviewed by interviewers who were not known to them.

Despite efforts made by the interviewers to avoid bias, this probably encouraged positive reports of the community service. Ideally, independent researchers should have been employed for all interviews to overcome potential bias but funding for this was not available.

The strength of the data is shown by the fact that data saturation was apparent after interviewing 16 clients, the consistency of some of the themes (such as the proximity of the community clinic) and the fact that there are few contradictory data. Although there is a paucity of published data at present concerning clients' experience of community STI services, what there is does seem to support the conclusions reached in this study. ${ }^{10}$

More research is needed to determine whether a community STI treatment service would be acceptable to client groups who do not currently use such a service.

\section{Acknowledgements}

The authors are most grateful to the women and men who consented to participate in this study and to Dr Paula Baraitser (PB) who contributed to the study design, data collection, and analysis and interpretation of the data.

\section{Statements on funding and competing interests}

Funding The Department of Sexual and Reproductive Health, Lewisham PCT provided funding for the gift vouchers.
Competing interests One of the authors (JE) was responsible for both implementing and evaluating the service studied. The author's detailed knowledge of the service was an advantage but the authors recognise the potential for this to bias their interpretation of the data. The authors actively sought to minimise the potential for bias at all stages of the study.

References

1 Adler MW. Sexual health - health of the nation. Sex Transm Infect 2003; 79: 85-87.

2 UK Collaborative Group for HIV and STI Surveillance. HIV and Other Sexually Transmitted Infections in the United Kingdom in 2003. Annual Report, November 2004. 2004. http://www.hpa. org.uk/infections/topics_AZ/hiv_and_sti/publications/annual20 04/annual2004.htm [Accessed 14 October 2006].

3 Djuretic T, Catchpole M, Bingham JS, Robinson A, Hughes G, Kinghorn G. Genitourinary medicine services in the United Kingdom are failing to meet current demand. Int J STD AIDS 2001; 12: 571-572.

4 Arowobusoye N. Lewisham Health Profile 2004. London, UK: Public Health Directorate, Lewisham Primary Care Trust, 2004.

5 Bradbeer C, Mears A. STI services in the United Kingdom: how shall we cope? Sex Transm Infect 2003; 79: 435-438.

6 Evans J, Baraitser P, Cross J, Bacon L. Piper J. Managing genital infection in community family planning clinics: an alternative approach to holistic sexual health provision. Sex Transm Infect 2004; 80: 142-144.

7 Evans D, Farquahar C. An interview based approach to seeking user views in genitourinary medicine. Genitourin Med 1996; 72: 223-226.

8 Scoular A, Duncan B, Hart G. "That sort of place ... where filthy men go ....": a qualitative study of women's perceptions of genitourinary medicine services. Sex Transm Infect 2001; 77: 340-343.

9 Pope C, Ziebland S, Mays N. Qualitative research in health care: analysing qualitative data. BMJ 2000; 320: 114-116.

10 Duncan B, Hart G, Scoular A, Bigrigg A. Qualitative analysis of psychosocial impact of diagnosis of Chlamydia trachomatis; implications for screening. BMJ 2001; 322: 195-199.

11 Wilkinson C, Massil H, Evans J. An interface of chlamydia testing by community family planning clinics and referral to hospital genitourinary medicine clinics. Br J Fam Plann 2000; 26: 206-209.

12 Vanhegan G, Wedgwood A. Do young people attend GU clinics when referred by a community based Brook Advisory Centre? Br J Fam Plann 1999; 25: 22-24.

\section{NEWS ROUNDUP}

\section{Healthcare Commission review of \\ sexual health}

The Healthcare Commission has released the findings of a review of data on sexual health that also highlights initiatives currently in place to improve sexual health in England and outlines the Commission's approach to assessing sexual health service delivery. The review has found that it is difficult to track progress and recognise where improvements are needed in sexual health because of gaps in the data currently available. As a result, services are limited in their ability to target groups at high risk, use data to plan and allocate resources where they are needed, or effectively monitor people's access to services and levels of sexual health.

\section{Leaflet on emergency contraception}

Brook has produced a new leaflet on emergency contraception aimed at young people. This is the latest addition to the Nothing But The Facts series of pocket-sized leaflets.

'Ask Brook' is a confidential helpline, online enquiry service and text information service. Young people can contact 'Ask Brook' free and in confidence on 08000185023 or by online enquiry at www.brook.org.uk. For automated information on key sexual health topics they can text 'BROOK INFO' to 81222. For details of the nearest young people's sexual health service they can text 'BROOK SERVICE' followed by their postcode and they will receive a reply within 24 hours.

\section{Wellbeing of Women booklet}

Over $50 \%$ of all women in the UK will experience a reproductive health problem during their lifetime. The charity, Wellbeing of Women, has produced a free information booklet to help women understand their bodies better so that they access help sooner. This forms part of the charity's Healthy Woman awareness campaign launched in August 2007.

The aim is to keep it simple and the message is that bodies are like any machine in that they need care, maintenance and repair. Women can use this booklet as a single point of reference to get the confidence to speak to their GP and receive the treatment they need.

For a copy of this free information booklet email wellbeingofwomen@rcog.org.uk or call 020 77726400

\section{Health Protection 2007 Conference}

The Health Protection Agency (HPA) annual conference in September focused on new scientific research and its application in practice.

A 1-day symposium on STIs formed part of the conference programme. This covered current public health priorities in sexual health, recent developments in infection and disease prevention strategies, and ethical and technical issues around tests and diagnosis There was also a session covering the latest developments in the National Chlamydia Screening Programme, and the current issues around HIV testing and screening strategies outside GUM settings.
For information about future HPA conferences visit the HPA website at www.healthprotectionconference.org.uk.

HRT and older women

New evidence confirms that hormone replacement therapy (HRT) should not be prescribed to older women who are many years past the menopause. The treatment will not help prevent chronic conditions such as heart disease in these women. The findings of the WISDOM study, which was conducted by the Medical Research Council's General Practice Research Framework and Clinical Trials Unit in collaboration with clinicians in Australia and New Zealand, are published on bmj.com.

Professor Janet Darbyshire, Director of the MRC Clinical Trials Unit, said: "There were more cases of angina, heart attack, sudden coronary death and blood clots in women taking the combined hormone therapy compared to women not taking HRT. The rates of stroke, breast and other cancers, fractures and overall deaths were not significantly different in these two groups".

Reference

1 Vickers MR, MacLennan AH, Lawton B, Ford D, Martin $\mathrm{J}$, Meredith SK, et al; WISDOM group. Main morbidities recorded in the Women's International (WIS of long Duration Oestrogen atter Menopause W 2007; 335: 239 [Epub 11 July 2007].

Reported by Henrietta Hughes, MRCGP, DFFP General Practitioner, London, UK 